\title{
Comparative genomics and molecular characterization of the maize PIN family proteins
}

\author{
Florent Villiers ${ }^{1}$ and June M. Kwak ${ }^{1,2,3 *}$ \\ Department of Cell Biology and Molecular Genetics, University of Maryland, College Park, MD, USA \\ 2 Department of Plant Science and Landscape Architecture, University of Maryland, College Park, MD, USA \\ ${ }^{3}$ Department of Plant Molecular Systems Biotechnology and Crop Biotech Institute, Kyung Hee University, Yongin, Republic of Korea \\ *Correspondence: jkwak@umd.edu
}

\section{A commentary on}

The maize PIN gene family of auxin transporters

by Forestan, C. (2012). Front. Plant Sci. 3:16. doi: 10.3389/fpls.2012.00016.

Owing to the recent advances in nucleic acid sequencing technologies, there has been exponential growth in genome sequencing and annotation over the last 10 years, especially in the field of plant biology. This phenomenon spans a wide variety of clades from algae to angiosperms, both monocots and dicots, and several databases and platforms have been published to hold and mine the generated data (Goodstein et al., 2011; Rouard et al., 2011; Van Bel et al., 2011). These databases include datasets and tools that allow one to perform comparative genomic analyses. Our understanding of evolution has been greatly enriched by such genome-wide approaches, notably by the ability to compare entire gene families across species (Delseny, 2009).

Among the various aspects of plant physiology that have drawn particular attention in functional and comparative genomics approaches, hormone biosynthetic, and signaling pathways stand out as the most studied, due to their regulatory roles in plant development and growth and biotic/abiotic stress responses (GomezPorras et al., 2007). Auxin, for instance, is the hormone responsible for shaping the plant, including establishing root and shoot architecture in response to developmental programs and environmental stimuli (Bohn-Courseau, 2010; Tromas and Perrot-Rechenmann, 2010). Precise regulation of plant development patterning is dependent upon the tight control of auxin repartition at both the tissue and the cellular level, which is ensured by a series of partially redundant transporters whose sub-cellular localization and activity are under constant adjustment. To date, three protein families have been identified for auxin transport activity: the AUX1 family is involved in the import of indole-3-acetic acid (IAA), and the PIN and ABCB families mainly function as exporters (Paponov et al., 2005; Geisler and Murphy, 2006). It is generally accepted that auxin entry into the cell mediated by AUX1 participates in polarized auxin flux (Kramer, 2004; Kramer and Bennett, 2006). In addition, the free diffusion of protonated IAA through the plasmalema accounts for some fraction of auxin entry, as it has been estimated that $17 \%$ of IAA ( $\mathrm{pKa}$ 4.85 ) is protonated in the apoplastic space (pH 5.5; Zazímalová et al., 2010). Once in the cytosol, however, it is exclusively present in its anionic form $\mathrm{IAA}^{-}$which is unable to cross the plasma membrane. Therefore, the release of IAA and its transfer to neighboring cells is mediated solely by active auxin exporters. The ABC-type transporters $\mathrm{ABCB} 1, \mathrm{ABCB} 4, \mathrm{ABCB} 14$, and $\mathrm{ABCB} 19$ have been characterized as possessing IAA transport activity, but do not seem to contribute to polarized auxin export (Titapiwatanakun and Murphy, 2009) because they are homogenously localized throughout the plasma membrane. On the contrary, PIN transporters can be targeted to specific regions of the plasmalemma and mediate polarized auxin flux from cell to cell (Blakeslee et al., 2005). In Arabidopsis, eight proteins belong to this family and share $32-85 \%$ identity at the amino acid level. Their respective roles in polarizing auxin transport rely on differences in sub-cellular localization and expression specificity. While AtPIN5 is relatively widely expressed at low levels (Krecek et al., 2009), AtPIN1, for instance, is exclusively expressed in aerial parts of the plant (Galweiler et al., 1998; Scarpella et al., 2006). AtPIN2 (Muller et al., 1998), AtPIN3 (Friml et al., 2002b), and AtPIN4 (Friml et al., 2002a) can be detected in the root tip where they mediate tropism and root patterning, and AtPIN8 is specifically expressed in pollen (Krecek et al., 2009).

Interestingly, phylogenetic analyses of the PIN family suggested that these proteins appeared with the rise of vascular plants, while $\mathrm{ABCB}$-type transporters are more ancient (Paponov et al., 2005; Zazimalova et al., 2007). Comparing AtPIN orthologs from monocots, such as rice (Wang et al., 2009), corn (Forestan et al., 2012), and sorghum (Shen et al., 2010), and dicots such as alfalfa (Schnabel and Frugoli, 2004), soybean, poplar, and A. lyrata (Krecek et al., 2009; Forestan and Varotto, 2010) clearly highlights a diversity of the organization of these transporters among various plant species. Particularly, the prevalence of monocot- (e.g., OsPIN10a, OsPIN10b, ZmPIN10a, ZmPIN10b, Bradi2g44990.1, Bradi2g15610.1) and dicot-specific (e.g., AtPIN3, AtPIN4, AtPIN7, POPTR 0010s12320.1, POPTR0008s12830.1). PIN transporters (Forestan and Varotto, 2010) raises the issue that simple sequence comparisons may not be sufficient to identify genes that are functionally related. Molecular characterization at the single gene/transcript/protein level is therefore required to establish similarities in terms of expression profile and/or protein activity, and to accurately identify candidates for, for instance, molecular manipulation in applied research.

Forestan and coworkers performed quite an exhaustive analysis aimed at ascertaining the maize counterparts of the Arabidopsis and rice PIN transporters. They identified 11 potential ZmPIN and ZmPIN-like genes, in addition to the three previously identified members of this family (Carraro et al., 2006; Forestan and 
Varotto, 2010), and proposed nomenclature by assigning each ZmPIN a name based on sequence similarity with Arabidopsis homologs. Next they assessed spatial and temporal expression of 14 ZmPIN and ZmPIN-like genes by RT-PCR, in situ hybridization, immunolocalization, and DR5-reporter lines. Their results reveal both tissue-specific (ZmPIN1d, ZmPIN9) and ubiquitous (ZmPIN1a, ZmPIN1b, ZmPIN1c) expression patterns, which are altered upon application of drugs (NAA, NPA) and in the br2 mutant. Based on this molecular study, the authors also propose that ZmPIN1a, ZmPIN1b, and ZmPIN1c, orthologs ofAtPIN1, could perform the functions of AtPIN3, AtPIN4, and AtPIN7, for which no orthologs have been identified in maize. This illustrates the necessity of performing molecular studies of individual genes in parallel with comparative functional genomic approaches. The use of a recently developed auxin reporter (Brunoud et al., 2012) and the database of auxin transport velocities (Kramer et al., 2011) should also contribute to the better characterization of auxin transport and physiology in non-model species.

\section{ACKNOWLEDGMENTS}

The work in the author's laboratory was supported by a grant (IOS-1025837) from NSF to June M. Kwak. The authors thank R. Bouten for critical reading of the manuscript.

\section{REFERENCES}

Blakeslee, J. J., Peer, W.A., and Murphy, A.S. (2005). Auxin transport. Curr. Opin. Plant Biol. 8, 494-500.

Bohn-Courseau, I. (2010). Auxin: a major regulator of organogenesis. C. R. Biol. 333, 290-296.

Brunoud, G., Wells, D. M., Oliva, M., Larrieu, A., Mirabet, V., Burrow, A. H., Beeckman, T., Kepinski, S., Traas, J., Bennett, M. J., and Vernoux, T. (2012). A novel sensor to map auxin response and distribution at high spatiotemporal resolution. Nature 482, 103-106.

Carraro, N., Forestan, C., Canova, S., Traas, J., and Varotto, S. (2006).ZmPIN1a and ZmPIN1b encode two novel putative candidates for polar auxin transport and plant architecture determination of maize. Plant Physiol. 142, 254-264.

Delseny, M. (2009). Le séquençage des génomes de plantes: vers une nouvelle révolution en biologie végétale. Cah. Agric. 18, 468-473.

Forestan, C., Farinati, S., and Varotto, S. (2012). The maize PIN gene family of auxin transporters. Front. Plant Sci. 3:16. doi: 10.3389/fpls.2012.00016

Forestan, C., and Varotto, S. (2010). PIN1 auxin efflux carriers localization studies in Zea mays. Plant Signal. Behav. 5, 436-439.

Friml, J., Benkova, E., Blilou, I., Wisniewska, J., Hamann, T., Ljung, K., Woody, S., Sandberg, G., Scheres, B., Jurgens, G., and Palme, K. (2002a). AtPIN4 mediates sink-driven auxin gradients and root patterning in Arabidopsis. Cell 108, 661-673.

Friml, J., Wisniewska, J., Benkova, E., Mendgen, K., and Palme, K. (2002b). Lateral relocation of auxin efflux regulator PIN3 mediates tropism in Arabidopsis. Nature 415, 806-809.

Galweiler, L., Guan, C., Muller, A., Wisman, E., Mendgen, K., Yephremov, A., and Palme, K. (1998). Regulation of polar auxin transport by AtPIN1 in Arabidopsis vascular tissue. Science 282, 2226-2230.

Geisler, M., and Murphy, A.S. (2006). The ABC of auxin transport: the role of p-glycoproteins in plant development. FEBS Lett. 580, 1094-1102.

Gomez-Porras, J. L., Riano-Pachon, D. M., Dreyer, I., Mayer, J.E., and Mueller-Roeber, B. (2007). Genomewide analysis of ABA-responsive elements ABRE and CE3 reveals divergent patterns in Arabidopsis and rice. BMC Genomics 8, 260. doi: 10.1186/1471-2164-8-260

Goodstein, D. M., Shu, S., Howson, R., Neupane, R., Hayes, R. D., Fazo, J., Mitros, T., Dirks, W., Hellsten, U., Putnam, N., and Rokhsar, D. S. (2011). Phytozome: a comparative platform for green plant genomics. Nucleic Acids Res. 40, 1178-1186.

Kramer, E. M. (2004). PIN and AUX/LAX proteins: their role in auxin accumulation. Trends Plant Sci. 9, 578-582.

Kramer, E. M., and Bennett, M. J. (2006). Auxin transport: a field in flux. Trends Plant Sci. 11,382-386.

Kramer, E. M., Rutschow, H. L., and Mabie, S. S. (2011). AuxV: a database of auxin transport velocities. Trends Plant Sci. 16, 461-463.

Krecek, P., Skupa, P., Libus, J., Naramoto, S., Tejos, R., Friml, J., and Zazimalova, E. (2009). The PINFORMED (PIN) protein family of auxin transporters. Genome Biol. 10, 249.

Muller, A., Guan, C., Galweiler, L., Tanzler, P., Huijser, P., Marchant, A., Parry, G., Bennett, M., Wisman, E., and Palme, K. (1998). AtPIN2 defines a locus of Arabidopsis for root gravitropism control. EMBO J. 17, 6903-6911.

Paponov, I. A., Teale, W. D., Trebar, M., Blilou, I., and Palme, K. (2005). The PIN auxin efflux facilitators: evolutionary and functional perspectives. Trends Plant Sci. 10, 170-177.

Rouard, M., Guignon, V., Aluome, C., Laporte, M.-A., Droc, G., Walde, C., Zmasek, C. M., Périn, C., and Conte, M. G. (2011). GreenPhylDB v2.0: comparative and functional genomics in plants. Nucleic Acids Res.39, D1095-D1102.

Scarpella, E., Marcos, D., Friml, J., and Berleth, T. (2006). Control of leaf vascular patterning by polar auxin transport. Genes Dev. 20, 1015-1027.

Schnabel, E. L., and Frugoli, J. (2004). The PIN and LAX families of auxin transport genes in Medicago truncatula. Mol. Genet. Genomics 272, 420-432.

Shen, C., Bai, Y., Wang, S., Zhang, S., Wu, Y., Chen, M., Jiang, D., and Qi, Y. (2010). Expression profile of PIN, AUX/LAX and PGP auxin transporter gene families in Sorghum bicolor under phytohormone and abiotic stress. FEBS J. 277, 2954-2969.

Titapiwatanakun, B., and Murphy, A. S. (2009). Posttranscriptional regulation of auxin transport proteins: cellular trafficking, protein phosphorylation, protein maturation, ubiquitination, and membrane composition. J. Exp. Bot. 60, 1093-1107.

Tromas, A., and Perrot-Rechenmann, C. (2010). Recent progress in auxin biology. C. R. Biol. 333, 297-306.

Van Bel, M., Proost, S., Wischnitzki, E., Mohavedi, S., Scheerlinck, C., Van De Peer, Y., and Vandepoele, K. (2011). Dissecting plant genomes with the PLAZA comparative genomics platform. Plant Physiol. 158, 590-600.

Wang, J.R., Hu, H., Wang, G. H., Li, J., Chen, J.Y., and Wu, P. (2009). Expression of PIN genes in rice (Oryza sativa L.): tissue specificity and regulation by hormones. Mol. Plant 2, 823-831.

Zazimalova, E., Krecek, P., Skupa, P., Hoyerova, K., and Petrasek, J. (2007). Polar transport of the plant hormone auxin - the role of PIN-FORMED (PIN) proteins. Cell. Mol. Life Sci. 64, 1621-1637.

Zazímalová, E., Murphy, A. S., Yang, H., Hoyerová, K., and Hosek, P. (2010). Auxin transporters - why so many? Cold Spring Harb. Perspect. Boil. 2, a001552.

Received: 10 February 2012; accepted: 19 February 2012; published online: 15 March 2012.

Citation: Villiers F and Kwak JM (2012) Comparative genomics and molecular characterization of the maize PIN family proteins. Front. Plant Sci. 3:43. doi: 10.3389/ fpls.2012.00043

This article was submitted to Frontiers in Plant Traffic and Transport, a specialty of Frontiers in Plant Science.

Copyright (C) 2012 Villiers and Kwak. This is an openaccess article distributed under the terms of the Creative Commons Attribution Non Commercial License, which permits non-commercial use, distribution, and reproduction in other forums, provided the original authors and source are credited. 